DOI: 10.20472/IAC.2018.036.010

\title{
UGUR ERDOGAN
}

Istanbul University Business School, Turkey

\section{STRATEGIC IMPORTANCE OF AIRPORT SLOTS IN AVIATION: SECONDARY SLOT MARKET AT LONDON HEATHROW AIRPORT}

\begin{abstract}
:
Airports are essential parts of the air transport system. As the gateways to aviation, they play a key role in facilitating tourism, travel, global trade and regional welfare. In 2016, airlines worldwide carried 3.8 billion people with an increase of $7 \%$ according to previous year. IATA's 20 -year forecast states that air passenger numbers will reach to seven billion annually by 2034 . The demand growth for air transport services is much higher than the growth of airport infrastructure. Shortage in airport capacity is one of the most important pressing issues affecting world air mobility today.

If capacity is less than demand, the demand needs to be managed. To use an airport at a specific time, an airline must have a slot. A Slot is most commonly known as landing or take-off right at airports during a specified period of time. The distribution of slots is carried by an independent "Slot co-ordinator".

London Heathrow Airport is the most heavily slot restricted airport in the world, and the slots are very valuable. At Heathrow, the slots in the slot pool is very limited. In 2016 only 3 pair of new slots given to airlines by the slot coordinator.

Because of the unavailability and lack of new slots, Heathrow has a premium secondary slot market, that makes it unique in the world. In 1999, the UK High Court gave a historic judgement about the question of buying and selling of slots and approved a slot deal between British Airways and KLM. By this approval, airlines are allowed to pay money to other airlines for slot transactions at UK airports. Although slot trading is still uncommon and technically illegal at EU airports, slots traded freely at Heathrow airport. In 2016, a gulf carrier, Oman Air purchased a prime slot pair from KLM for 75 million USD. The previous record was 60 million USD for a slot pair American Airlines bought from SAS a year before.

Airport slots are not always used by airlines that attach the highest value to them on behalf of airport side. The efficient use of airport capacity means uses of larger aircraft, longer average flight lengths, and higher passenger numbers for allocated slots. If there is an inadequate use of a slot by a short-haul and less passenger flight, buying of this slot by another airline for a long-haul flight can create additional value and efficiency to that slot time.
\end{abstract}

\section{Keywords:}

Air transport, airport slots, airport capacity, grandfather rights, competitive advantage, secondary slot trading. 